\title{
Efficacy of rapid on-site evaluation for diagnosing pulmonary lesions and mediastinal lymph nodes: a systematic review and meta-analysis
}

\author{
Xi Chen ${ }^{1 \#}$, Bing Wan ${ }^{2 \#}$, Yangyang $\mathrm{Xu}^{3 \#}$, Yong Song ${ }^{1,3,4}$, Ping Zhan ${ }^{1,3,4}$, Litang Huang ${ }^{4}$, Hongbing Liu ${ }^{1,3,4}$, \\ Dang Lin ${ }^{5}$, Tangfeng Lv ${ }^{1,3,4}$
}

${ }^{1}$ Department of Respiratory and Critical Care Medicine, Jinling Hospital, Nanjing University School of Medicine, Nanjing 210002, China; ${ }^{2}$ Department of Respiratory and Critical Care Medicine, The Affiliated Jiangning Hospital of Nanjing Medical University, Nanjing 210002, China; ${ }^{3}$ Department of Respiratory and Critical Care Medicine, Jinling Hospital, Nanjing Medical University, Nanjing 210002, China; ${ }^{4}$ Department of Respiratory and Critical Care Medicine, Jinling Hospital, Medical School of Southeast University, Nanjing 210002, China; ${ }^{5}$ Department of Respiratory and Critical Care Medicine, The Affiliated Suzhou Hospital of Nanjing Medical University, Suzhou 215001, China

Contributions: (I) Conception and design: All authors; (II) Administrative support: Y Song, T Lv, D Lin; (III) Provision of study materials or patients: All authors; (IV) Collection and assembly of data: X Chen, B Wan, L Huang; (V) Data analysis and interpretation: X Chen, P Zhan, H Liu, B Wan, Y Xu; (VI) Manuscript writing: All authors; (VII) Final approval of manuscript: All authors.

"The authors have contributed equally to this work.

Correspondence to: Dang Lin. Department of Respiratory and Critical Care Medicine, The Affiliated Suzhou Hospital of Nanjing Medical University, 16 West BAITA Road, Suzhou 215001, China. Email: Danglin4067@163.com; Tangfeng Lv. Department of Respiratory and Critical Care Medicine, Jinling Hospital, Nanjing University School of Medicine, Nanjing 210002, China. Email: bairoushui@163.com.

Background: Although rapid on-site evaluation (ROSE) is gradually becoming an integral part of the modern Interventional Pulmonology, the clinical benefit of ROSE is still a matter of controversy. The objective of this meta-analysis was to clarify whether ROSE is effective in diagnosing pulmonary lesions and mediastinal lymph nodes, synchronously, to assess circumstances under which ROSE makes more sense.

Methods: MEDLINE and EMBASE were searched for studies comparing any outcome between ROSE and no-ROSE group in diagnosing pulmonary lesions and mediastinal lymph nodes. Statistical calculations were conducted using Review Manager, version 5.3, and Stata Release 12.0. Meta-analysis was completed using a random-effects model when $\mathrm{I}^{2} \geq 50 \%$ or a fixed-effect otherwise. Heterogeneity was assessed by the $\mathrm{I}^{2}-$ statistic test. Publication bias was assessed by the Begg's test.

Results: This Literature search yielded 27 studies altogether. The pooled risk difference of adequate rate was 0.12 [95\% confidence intervals (CI): 0.07-0.16, $\mathrm{I}^{2}=0 \%$ ], the combined risk difference (RD) of diagnostic yield was 0.14 (95\% CI: $0.09-0.18, \mathrm{I}^{2}=57 \%$ ) while the pooled $\mathrm{RD}$ of sensitivity for malignancy was 0.10 (95\% CI: 0.06-0.14, $\mathrm{I}^{2}=20 \%$ ). Significant heterogeneity only existed in diagnostic yield $\left(\mathrm{I}^{2}=57 \%, \mathrm{P}=0.001\right)$. Further subgroup analysis documented a higher increase in diagnostic yield when sampling solid pulmonary lesions than sampling hilar/mediastinal lymph nodes 0.16 (95\% CI: $\left.0.12-0.20, \mathrm{I}^{2}=0 \%\right)$ versus 0.08 (95\% CI: $\left.0.04-0.13, \mathrm{I}^{2}=10 \%\right)$ and when applied to patients with suspected/diagnosed lung cancer than unselected patients 0.12 (95\% CI: 0.06 to 0.18 ) versus 0.11 (95\% CI: -0.07 to 0.28 ).

Conclusions: ROSE is a useful technology in diagnosing pulmonary lesions and mediastinal lymph nodes, especially when sampling solid pulmonary lesions or applied to patients with suspected lung cancer.

Keywords: Mediastinal lymph nodes; meta-analysis; pulmonary lesions; rapid on-site evaluation (ROSE)

Submitted Jun 27, 2019. Accepted for publication Nov 28, 2019.

doi: $10.21037 /$ tlcr.2019.12.13

View this article at: http://dx.doi.org/10.21037/tlcr.2019.12.13 


\section{Introduction}

With a cytopathologist present on-site, rapid on-site evaluation (ROSE) can provide real-time feedback on the quality and quantity of needle biopsy samples. Specimens with the presence of excess blood or massive necrosis or numerous bronchial epithelial cells without adequate malignant cells and lymphocytes are identified by cytopathologists, guiding operators to change the site, depth or angle for the pinpoint. In like manner, once an adequate or diagnostic specimen is provided, operators are conducted to stop further trials and thus avoiding patients from additional procedures. Theoretically, ROSE offers advantages.

In early time, Davenport found that the inadequate rate of specimens by bronchoscopy decreases from $56 \%$ to $18 \%$ with the help of ROSE (1). Shortly afterward, several observational studies showed an increase with ROSE in diagnostic yield or adequate rate either by transthoracic fine needle aspiration (TTFNA) (2-5) or transbronchial needle aspiration (TBNA) with or without the guide of endobronchial ultrasound (EBUS) (6-9). Besides increasing the yield, ROSE also has the potential to decrease the complication rate by reducing the number of puncture sites or needle passes and avoiding additional diagnostic procedures (9-12). What's more, the utilization of ROSE is promising in saving the cost $(10,13)$ and providing more cells for the ancillary test $(14,15)$. With considerable merits showing above, ROSE is gradually becoming an integral technology in the modern Interventional Pulmonology.

However, the clinical benefit of ROSE is still a matter of controversy. A random controlled trial (RCT) conducted by Yarmus et al. failed to suggest a higher diagnostic yield with ROSE: ROSE, 55\%; no-ROSE, 53\% (P=1.000) (11). It is not unique but has its counterpart. Trisolini and his colleagues also found no significant difference in diagnostic yield between the ROSE and no-ROSE group in their RCT: ROSE, 78.3\%; no-ROSE, 75.3\% ( $\mathrm{P}=0.64)$ (9). Opposition to the utilization of ROSE is provoked for the disappointing result on improving the diagnostic yield. The above two RCTs sampled lymph nodes in unselected patients with enlarged hilar/mediastinal nodes while there are additional RCTs $(3,5)$ in which solid pulmonary lesions were sampled and all of these studies reported a considerable increase in diagnostic yield with ROSE. It is supposed that ROSE should be recommended in selected patients.

Consequently, this systemic review and meta-analysis aimed to conduct a comprehensive literature review not restricting study design, population, diagnostic method or sampling sites to clarify whether ROSE is useful for diagnosing pulmonary lesions and mediastinal lymph nodes, synchronously, to assess circumstances under which ROSE makes more sense.

\section{Methods}

This systematic review was conducted following guidelines of PRISMA (Preferred Reporting Items for Systematic Reviews and Meta-analyses) statement (16) to assess the efficacy of rapid on-site evaluation for diagnosing pulmonary lesions and mediastinal lymph nodes.

\section{Literature search}

The MEDLINE (using PubMed as the search engine) and EMBASE databases were first searched on 13 October and last updated on December 11, 2018 with the following search strings: ((rapid on-site evaluation [Title/Abstract] OR ROSE [Title/Abstract] OR rapid on-site cytologic evaluation [Title/Abstract] OR immediate cytologic evaluation [Title/Abstract])) AND (lung OR pulmonary OR mediastinal). Only publications in English or Chinese language were screened, and there was no restriction on time or study design. SCOPUS, Web of Science and Google Scholar were also searched for the reference list of all the articles included.

\section{Inclusion criteria}

Original studies compared any outcome (e.g., adequate rate, diagnostic yield, sensitivity, accuracy, number of biopsy site, number of needle passes, complication rate, cost, ancillary test) between ROSE and no-ROSE group for diagnosing pulmonary lesions or mediastinal lymph nodes were eligible for inclusion. Two independent authors (Chen and Huang) reviewed all the titles/abstracts and selected studies meeting the following inclusion criteria. Disagreements were solved by discussion.

\section{Exclusion criteria}

(I) Review articles, letters, comments, editorials, case reports. (II) Abstract or conference abstract without full text available. (III) Studies not providing outcomes of ROSE group and no-ROSE group separately. (IV) Studies not providing the results of pulmonary lesions or mediastinal lymph nodes. 


\section{Quality assessment}

Study quality was assessed utilizing the QUADAS2(Quality Assessment of Diagnostic Accuracy Studies) tool. Risk of bias and concerns about applicability was evaluated synchronously in QUADAS-2. Risk of bias was assessed as low, high, or unclear in four main components: patient selection, index test, reference standard and, flow and timing. Concerns about lack of applicability were assessed in patient selection, index test, and reference standard.

\section{Data extraction}

Two authors (Chen and Huang) independently extracted the following data onto standardized data extraction forms utilizing Excel: (I) publication details (authors, year of publication, country); (II) basic characteristics (study design, number of patients, diagnostic method, population, main sampling sites); (III) diagnostic indices: adequate rate, diagnostic yield, sensitivity for malignancy. (Adequate means that it contains sufficient cells for a diagnosis; Diagnostic means that not only sufficient material provided but also a specific diagnosis made (non-adequate cases were excluded); Sensitivity for malignancy is the ratio of malignant diagnosis in all malignant cases diagnosed by histopathology or clinical follow-up (non-diagnostic cases were excluded); (IV) procedural details: number of biopsy sites, number of needle passes, procedure time, complication rate; (V) other endpoints: concordance between ROSE and final diagnosis, cost, ancillary test.

\section{Data analysis}

All statistical analyses were performed by Revman (Review Manager, version 5.3: The Nordic Cochrane Centre, The Cochrane Collaboration, 2014) and Stata Release 12 (Stata Corp., College Station, TX, USA). The primary endpoints were diagnostic indices like adequate rate, diagnostic yield, and sensitivity for malignancy. Secondary endpoints were the amount of biopsy sites, amount of needle passes, procedure time, complication rate, cost, ancillary test, and concordance between ROSE and the final diagnosis. The risk difference (RD) with $95 \%$ confidence interval (CI) of each study was calculated for dichotomous variables. The mean difference (MD) with $95 \%$ CI of each study was calculated for continuous variables. A meta-analysis of concordance between ROSE and the final diagnosis was completed in the 'metan' routine defined in Stata. All the individual study estimates were pooled using a fixed effects model when the $\mathrm{I}^{2}<50 \%$, otherwise a random effects model was used. Forest plots were generated to display the combined estimates. The impact of heterogeneity in the individual outcomes was assessed using the $\mathrm{I}^{2}$ test and Cochrane Q statistic. An $I^{2}$ value $\geq 30 \%$ indicates significant heterogeneity, equally, a $\mathrm{P}$ value $<0.1$ in the Cochrane $\mathrm{Q}$ test was considered to be significant. The presence of publication bias was evaluated utilizing the Begg's funnel plot and Begg's test. The plot resembles a symmetrical funnel and the $\mathrm{P}$ value $<0.05$ in the absence of publication bias. Subgroup analysis was carried out to compare different characteristics among included studies to analyze the heterogeneity and figure out under what circumstance ROSE makes more sense. Studies were evaluated and dichotomized according to study design (RCT or not-RCT), main sampling sites (solid pulmonary lesions or hilar/mediastinal lymph nodes), diagnostic methods (c-TBNA or EBUS-TBNA or TTFNA) and population (suspected/diagnosed lung cancer or unselected patients). Meta-regression was also performed to quantitatively determine whether the yield was related to previously defined subgroups.

\section{Results}

\section{Summary of studies included}

An initial search of MEDLINE and EMBASE databases yielded 7040 unique study titles and abstracts (3340 PUBMED, 5727 EMBASE). Screening of titles and abstracts provided a set of 138 studies eligible for inclusion. After reading the full text of these articles, only 21 studies (3,5,7,9-15,17-27) met our inclusion criteria. References list of the studies included provided additional 6 studies $(1,2,4,6,8,28)$. Altogether, 27 studies were eligible to claim a qualitative and quantitative analysis. The flowchart of study selection process was shown in Figure 1.

The majority of the studies were prospective or retrospective cohort studies (19 out of 27) while 8 out of 27 were random controlled trials (RCTs). Diagnostic methods were multiple (5 c-TBNA, 11 EBUS-TBNA, 2 combined c-TBNA and EBUS-TBNA, 4 TTFNA, 1 FOB, 1 r-EBUS, 1 c-EBNA, 1 EBUS-FNA, 1 not restricted). Lymph nodes were mostly sampled in 17 studies. Pulmonary masses/ nodules were sampled most in 8 studies, while the number of sampled lymph nodes and lung masses/nodules is equivalent in one study and the information of sampled lesions was not available in only one study. Some studies 


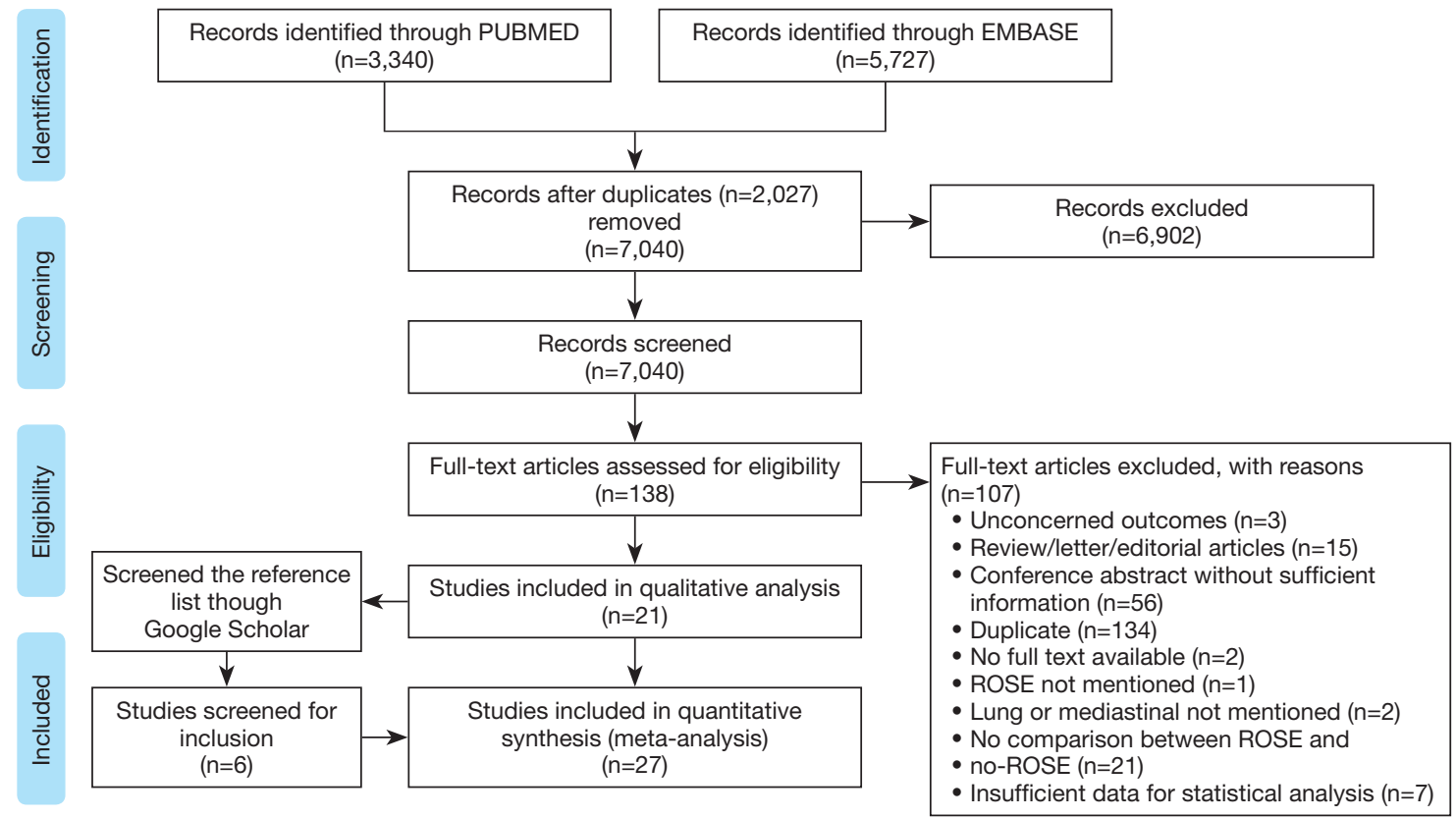

Figure 1 PRISMA study flow diagram.

enrolled patients with suspected or diagnosed lung cancer; some were conducted in unselected practice, only 1 study included patients with suspected sarcoidosis, the remaining 3 studies enrolled patients with SPN, PPL and central pulmonary lesions (Table 1). Adequate rate, diagnostic yield, and sensitivity for malignancy were reported on a per-case basis in 5, 18, and 12 studies, respectively. Nine studies were noticed to compare the number of biopsy sites and 13 compared the number of needle passes. The contrast of procedure time and complication rate between ROSE group and No-ROSE group were reported in 10 and 14 studies. Comparison of the cost was presented in 2 studies. The ancillary test was mentioned about in 4 studies. Concordance between ROSE and the final diagnosis can be extracted from 9 studies (Table 2).

Chin et al. 2002 (8) was excluded from the further metaanalysis. The primary endpoint of this study was to ascertain the average number of aspirates needed to make a definite cytological diagnosis successfully. The maximum number of aspirates with ROSE reached 7, which was applicable in daily clinical practice and greatly affected the diagnose efficacy.

\section{Quality assessment}

A quality assessment utilizing QUADAS-2 is displayed in
Table 3. The overall risk of bias was low in 7 studies, the overall concerns about applicability were low in 9 studies, and seven of these studies met both conditions.

\section{Primary endpoints}

\section{Adequate rate}

Figure $2 \mathrm{~A}$ showed the forest plot of pooled adequate rate. The meta-analysis of adequate rate assessed in 5 studies $(3,5,11,17,27)$ was $0.12\left(I^{2}=0 \%\right)$ using fixed-efforts, with the individual $\mathrm{RD}$ of adequacy varied from 0.07 to 0.16 (Figure 2A).

\section{Diagnostic yield}

Eighteen studies (2,4-6,9-13,17-19,22-27) provided the data of diagnostic yield and Madan et al. (23) conducted the cohort study in both c-TBNA and EBUS-TBNA group. On average, the conjunction of ROSE led to a $14 \%$ improvement (95\% CI: $0.09-0.18, \mathrm{I}^{2}=57 \%$ ) in diagnostic yield (Figure 2B).

\section{Sensitivity for malignancy}

With ROSE, the average increase of sensitivity for malignancy assessed in 12 studies $(2,3,5,10-13,17,21,24,25,27)$ was $10 \%$ ranging from $6 \%$ to $14 \%$ (Figure $2 C$ ). 
Table 1 Basic characteristic of included studies (Part A)

\begin{tabular}{|c|c|c|c|c|c|c|c|c|c|c|}
\hline \multirow[t]{2}{*}{ Author year } & \multirow[t]{2}{*}{ Country } & \multirow{2}{*}{$\begin{array}{l}\text { Study } \\
\text { design }\end{array}$} & \multirow{2}{*}{$\begin{array}{c}\text { No. of } \\
\text { patients }\end{array}$} & \multirow{2}{*}{$\begin{array}{l}\text { Sampling } \\
\text { method }\end{array}$} & \multirow{2}{*}{$\begin{array}{c}\text { Main sampling } \\
\text { sites }\end{array}$} & \multirow[t]{2}{*}{ Population } & \multicolumn{2}{|c|}{$\begin{array}{l}\text { No. of biopsy } \\
\text { sites }\end{array}$} & \multicolumn{2}{|c|}{$\begin{array}{l}\text { No. of needle } \\
\text { passes }\end{array}$} \\
\hline & & & & & & & $\mathrm{R}$ & NR & $\mathrm{R}$ & NR \\
\hline $\begin{array}{l}\text { Yarmus et al., } \\
2011\end{array}$ & America & $\mathrm{RCT}$ & 68 & C-TBNA & Lymph nodes & $\begin{array}{l}\text { Unselected patients } \\
\text { with enlarged hilar/ } \\
\text { mediastinal lymph } \\
\text { nodes }\end{array}$ & NA & NA & 4.47 & 4.14 \\
\hline Oki et al., 2013 & Japan & $\mathrm{RCT}$ & 108 & EBUS-TBNA & Lymph nodes & $\begin{array}{l}\text { Patients suspected } \\
\text { for lung cancer }\end{array}$ & NA & NA & $2.2 \pm 0.9$ & $3.1 \pm 0.4$ \\
\hline $\begin{array}{l}\text { Trisolini et al., } \\
2015\end{array}$ & Italy & $\mathrm{RCT}$ & 197 & EBUS-TBNA & Lymph nodes & $\begin{array}{l}\text { Patients with known } \\
\text { or Suspected lung } \\
\text { cancer }\end{array}$ & $1.3 \pm 0.5$ & $1.4 \pm 0.5$ & 4 & 4 \\
\hline $\begin{array}{l}\text { Murakami } \\
\text { et al., } 2013\end{array}$ & Japan & RCS & 98 & EBUS-TBNA & Lymph nodes & $\begin{array}{c}\text { Patients with } \\
\text { diagnosed small cell } \\
\text { lung cancer }\end{array}$ & 1.1 & 1.6 & 2.3 & 4.0 \\
\hline Li et al., 2014 & China & RCS & 69 & EBUS-TBNA & Lymph nodes & $\begin{array}{c}\text { Patients with } \\
\text { diagnosed lung } \\
\text { cancer }\end{array}$ & NA & NA & $2.4 \pm 0.2$ & $4.6 \pm 0.4$ \\
\hline $\begin{array}{l}\text { Chin et al. } \\
2002\end{array}$ & America & PCS & 79 & C-TBNA & Lymph nodes & $\begin{array}{l}\text { Unselected patients } \\
\text { underwent c-TBNA }\end{array}$ & NA & NA & $6.2 \pm 2.5$ & $4.5 \pm 1.7$ \\
\hline $\begin{array}{l}\text { Cardoso et al. } \\
2015\end{array}$ & Portugal & PCS & 81 & EBUS-TBNA & Lymph nodes & $\begin{array}{c}\text { Unselected patients } \\
\text { underwent EBUS- } \\
\text { TBNA }\end{array}$ & NA & NA & $3.4 \pm 1.7$ & $4.5 \pm 1.7$ \\
\hline $\begin{array}{l}\text { Mondoni et al., } \\
2013\end{array}$ & Italy & RCS & 125 & c-EBNA & $\begin{array}{c}\text { Pulmonary } \\
\text { nodules/masses }\end{array}$ & $\begin{array}{l}\text { Patients with } \\
\text { suspected central } \\
\text { lung cancer }\end{array}$ & NA & NA & NA & NA \\
\hline $\begin{array}{l}\text { Baram et al., } \\
2005\end{array}$ & America & PCS & 42 & $\begin{array}{c}\text { c-TBNA/EBUS- } \\
\text { TBNA }\end{array}$ & Lymph nodes & $\begin{array}{c}\text { Unselected patients } \\
\text { underwent TBNA }\end{array}$ & 1.4 & 1.8 & $2.8 \pm 1.0$ & $3.2 \pm 1.2$ \\
\hline $\begin{array}{l}\text { Chen et al., } \\
2015\end{array}$ & China & RCS & 815 & $\begin{array}{l}\text { r-EBUS+TBB/ } \\
\text { brushing }\end{array}$ & $\begin{array}{c}\text { Pulmonary } \\
\text { nodules/masses }\end{array}$ & $\begin{array}{c}\text { Patients with } \\
\text { peripheral } \\
\text { pulmonary lesions }\end{array}$ & NA & NA & NA & NA \\
\hline $\begin{array}{l}\text { Diette et al., } \\
2000\end{array}$ & America & PCS & 204 & FOB & NA & $\begin{array}{l}\text { Unselected patients } \\
\text { underwent FOB }\end{array}$ & NA & NA & 5.2 & 4.4 \\
\hline
\end{tabular}

Table 1 (continued) 
Table 1 (continued)

\begin{tabular}{|c|c|c|c|c|c|c|c|c|c|c|}
\hline \multirow[t]{2}{*}{ Author year } & \multirow[t]{2}{*}{ Country } & \multirow{2}{*}{$\begin{array}{l}\text { Study } \\
\text { design }\end{array}$} & \multirow{2}{*}{$\begin{array}{c}\text { No. of } \\
\text { patients }\end{array}$} & \multirow{2}{*}{$\begin{array}{l}\text { Sampling } \\
\text { method }\end{array}$} & \multirow{2}{*}{$\begin{array}{l}\text { Main sampling } \\
\text { sites }\end{array}$} & \multirow[t]{2}{*}{ Population } & \multicolumn{2}{|c|}{$\begin{array}{l}\text { No. of biopsy } \\
\text { sites }\end{array}$} & \multicolumn{2}{|c|}{$\begin{array}{l}\text { No. of needle } \\
\text { passes }\end{array}$} \\
\hline & & & & & & & $\mathrm{R}$ & NR & $\mathrm{R}$ & NR \\
\hline $\begin{array}{l}\text { Saleh et al., } \\
1996\end{array}$ & America & $\mathrm{RCS}$ & 159 & CT-guided FNA & $\begin{array}{c}\text { Pulmonary } \\
\text { nodules/masses }\end{array}$ & NA & NA & NA & NA & NA \\
\hline $\begin{array}{l}\text { Küçük et al., } \\
2004\end{array}$ & Turkey & $\mathrm{RCT}$ & 96 & CT-guided FNA & $\begin{array}{c}\text { Pulmonary } \\
\text { nodules/masses }\end{array}$ & $\begin{array}{c}\text { Patients with } \\
\text { diagnosed lung } \\
\text { cancer }\end{array}$ & NA & NA & NA & NA \\
\hline $\begin{array}{l}\text { Collins et al., } \\
2012\end{array}$ & America & RCS & 680 & EBUS-FNA & Lymph nodes & $\begin{array}{c}\text { Unselected patients } \\
\text { underwent EBUS- } \\
\text { FNA }\end{array}$ & 1.394 & 2.085 & NA & NA \\
\hline $\begin{array}{l}\text { Griffin et al., } \\
2010\end{array}$ & America & RCS & 149 & EBUS-TBNA & Lymph nodes & $\begin{array}{c}\text { Unselected patients } \\
\text { underwent EBUS- } \\
\text { TBNA }\end{array}$ & NA & NA & NA & NA \\
\hline $\begin{array}{l}\text { Guo et al., } \\
2015\end{array}$ & China & RCS & 236 & EBUS-TBNA & Lymph nodes & $\begin{array}{c}\text { Patients with known } \\
\text { or suspected lung } \\
\text { cancer }\end{array}$ & 2.1 & 2.3 & 2.7 & 2.9 \\
\hline $\begin{array}{l}\text { Wong et al., } \\
2014\end{array}$ & America & RCS & 178 & EBUS-TBNA & Lymph nodes & $\begin{array}{c}\text { Unselected patients } \\
\text { underwent EBUS- } \\
\text { TBNA }\end{array}$ & $1.5 \pm 0.7$ & $1.9 \pm 0.8$ & $2.5 \pm 0.9$ & $2.5 \pm 1.0$ \\
\hline $\begin{array}{l}\text { Kern et al., } \\
2012\end{array}$ & Slovenia & PCS & 385 & Not restricted & Equivalent & $\begin{array}{c}\text { Unselected patients } \\
\text { underwent TBNA } \\
\text { FNA }\end{array}$ & NA & NA & NA & NA \\
\hline
\end{tabular}

RCT, random controlled trial; RCS, retrospective cohort study; PCS, prospective cohort study; c-TBNA, conventional transbronchial needle aspiration; EBUS, endobronchial ultrasound; c-EBNA, conventional endobronchial needle aspiration; r-EBUS, radial probe endobronchial ultrasound; TBB, transbronchial biopsy; FOB, fiberoptic bronchoscopy; ROSE, rapid on-site evaluation; NR, without rapid on-site evaluation; NA, not available. 
Table 2 The basic characteristics of the included studies (Part B)

\begin{tabular}{|c|c|c|c|c|c|c|c|c|c|c|}
\hline \multirow{2}{*}{ Author year } & \multicolumn{3}{|c|}{ Diagnostic outcome } & \multicolumn{2}{|c|}{ Procedure time } & \multicolumn{2}{|c|}{$\begin{array}{l}\text { Complication } \\
\text { rate }\end{array}$} & \multirow{2}{*}{ Cost } & \multirow{2}{*}{$\begin{array}{c}\text { Ancillary } \\
\text { test }\end{array}$} & \multirow{2}{*}{$\begin{array}{c}\text { Concordance } \\
\text { between } \\
\text { ROSE and fina } \\
\text { diagnosis }\end{array}$} \\
\hline & Adequacy & $\begin{array}{c}\text { Diagnostic } \\
\text { yield }\end{array}$ & $\begin{array}{l}\text { Sensitivity for } \\
\text { malignancy }\end{array}$ & $\mathrm{R}$ & NR & $\mathrm{R}$ & NR & & & \\
\hline \multicolumn{11}{|l|}{ Madan et al., 2016} \\
\hline c-TBNA & NA & Reported & NA & $21 \pm 2.8$ & $20 \pm 3.8$ & $0 / 20$ & $1 / 20$ & NA & NA & NA \\
\hline Yarmus et al., 2011 & Reported & Reported & Reported & 29.5 & 27.6 & NA & NA & NA & NA & NA \\
\hline Oki et al.2013 & NA & Reported & Reported & $22.3 \pm 15.9$ & $22.1 \pm 7.7$ & $0 / 55$ & $0 / 53$ & NA & NA & NA \\
\hline Trisolini et al., 2015 & Reported $^{a}$ & Reported & NA & $17.8 \pm 8.34$ & $17.9 \pm 5.61$ & $3 / 98$ & $4 / 99$ & NA & Reported & NA \\
\hline Trisolini et al., 2011 & Reported $^{\mathrm{a}}$ & Reported & NA & NA & NA & $5 / 83$ & $17 / 85$ & NA & NA & Reported \\
\hline Chin et al., 2002 & NA & Reported & NA & NA & NA & NA & NA & NA & NA & NA \\
\hline Bruno et al., 2013 & NA & Reported & Reported & NA & NA & NA & NA & Reported & NA & NA \\
\hline Gianella et al., 2018 & NA & NA & Reported & NA & NA & NA & NA & NA & NA & NA \\
\hline Cardoso et al., 2015 & Reported & Reported & Reported & NA & NA & $0 / 41$ & $0 / 40$ & NA & NA & NA \\
\hline Mondoni et al., 2013 & NA & Reported & Reported & NA & NA & NA & NA & NA & NA & NA \\
\hline Baram et al., 2005 & NA & Reported $^{\mathrm{a}}$ & Reported $^{a}$ & $39 \pm 20$ & $39 \pm 14$ & $0 / 32$ & $0 / 12$ & NA & NA & Reported \\
\hline Chen et al., 2015 & NA & Reported & NA & $28.12 \pm 6.67$ & $27.7 \pm 8.40$ & NA & NA & NA & NA & Reported \\
\hline Davenport et al., 1990 & Reported $^{a}$ & NA & Reported $^{a}$ & NA & NA & NA & NA & NA & NA & Reported \\
\hline Collins et al., 2012 & Reported $^{\mathrm{a}}$ & Reported $^{a}$ & NA & NA & NA & NA & NA & NA & NA & NA \\
\hline \multicolumn{11}{|l|}{ Gariffin et al., 2010} \\
\hline Lymph nodes & NA & Repprted $^{a}$ & NA & NA & NA & NA & NA & NA & Reported & NA \\
\hline Lung lesions & NA & Repprted $^{a}$ & NA & NA & NA & NA & NA & NA & & NA \\
\hline Guo et al., 2015 & Reported & Repprted $^{a}$ & NA & 37.6 & 37.4 & $0 / 122$ & $0 / 114$ & NA & NA & NA \\
\hline Xiang et al., 2018 & Reported & Reported & Reported & NA & NA & $1 / 81$ & $7 / 60$ & NA & NA & Reported \\
\hline Chaiyakul et al., 2018 & NA & Reported & NA & $32.33 \pm 6.50$ & $50.32 \pm 4.99$ & NA & NA & NA & NA & Reported \\
\hline Wong et al., 2014 & NA & NA & NA & NA & NA & NA & NA & NA & Reported & Reported \\
\hline Kern et al., 2012 & NA & Reported & NA & NA & NA & NA & NA & NA & NA & NA \\
\hline
\end{tabular}

a, reported in per-lesion or per-speciman basis. c-TBNA, conventional transbronchial needle aspiration; EBUS, endobronchial ultrasound; ROSE, rapid on-site evaluation; NR, without rapid on-site evaluation; NA, not available. 
Table 3 Quality assessment utilizing QUADAS-2

\begin{tabular}{|c|c|c|c|c|c|c|c|}
\hline Author-year & \multicolumn{4}{|c|}{ Risk of bias } & \multicolumn{3}{|c|}{ Applicability Concerns } \\
\hline Madan et al., 2016 & Low & Low & High & Low & Low & Low & High \\
\hline Yarmus et al., 2011 & Low & Low & Low & Low & Low & Low & Low \\
\hline Oki et al., 2013 & Low & Low & High & Low & Low & Low & High \\
\hline Trisolini et al., 2011 & Low & Low & Low & Low & Low & Low & Low \\
\hline Murakami et al., 2013 & High & Low & Low & Low & High & Low & Low \\
\hline Li et al., 2014 & High & Low & Low & Low & High & Low & Low \\
\hline Bruno et al., 2013 & Low & Low & Low & Low & Low & Low & Low \\
\hline Mondoni et al., 2013 & High & Low & Low & Low & High & Low & Low \\
\hline Baram et al., 2005 & Unclear & Low & Low & Low & Unclear & Low & Low \\
\hline Chen et al., 2015 & Low & Low & High & High & Low & Low & High \\
\hline Diette et al., 2000 & Low & Low & High & Low & Low & Low & High \\
\hline Austin et al., 1993 & High & Low & Low & Low & High & Low & Low \\
\hline $\begin{array}{l}\text { Santambrogio et al., } \\
1997\end{array}$ & Low & Low & Low & Low & Low & Low & Low \\
\hline Saleh et al., 1996 & Unclear & Low & High & Unclear & Unclear & Low & High \\
\hline Xiang et al., 2018 & Low & Low & High & Low & Low & Low & High \\
\hline Chaiyakul et al., 2018 & Low & Low & Low & Low & Low & Low & Low \\
\hline Wong et al., 2014 & Low & Low & High & Low & Low & Low & High \\
\hline Kern et al., 2012 & Low & Low & Unclear & Unclear & Low & Low & Unclear \\
\hline
\end{tabular}

\section{Secondary endpoints}

Amount of sampled sites and needle passes

Nine and 13 studies severally compared the amount of sampled lesions or needle passes between the ROSE and no-ROSE group, and only $4(3,21,26,28)$ and 7 $(2,7,10,12,17,18,28)$ of these studies severally provided enough data for meta-analysis. The pooled MD pointed out that ROSE did not affect the amount of sampled sites
(-0.11, 95\% CI: -0.29 to 0.08 ) (Figure $3 A$ ) but was inclined to decrease the amount of needles passes $(-0.99,95 \% \mathrm{CI}$ : -1.89 to -0.09$)$ (Figure 3B).

\section{Procedure time and complication rate}

Although the contrast of procedure time was mentioned in 9 studies, 3 of them lack ample data for meta-analysis. Pooled procedure time of the remaining 6 studies 


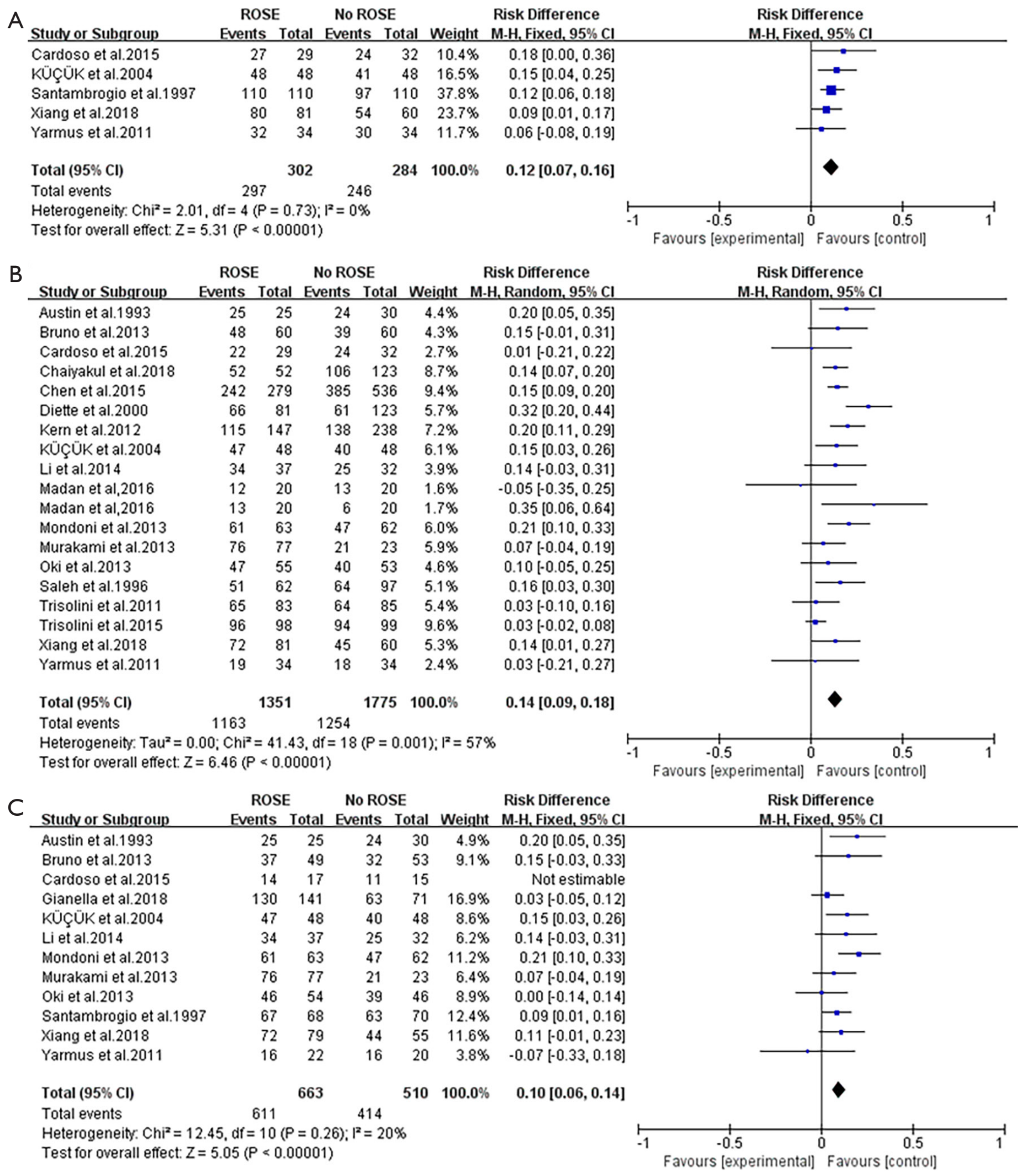

Figure 2 Forest plots of primary endpoints. (A) Forest plot of the RD comparing the adequate rate of ROSE or without ROSE in the included studies; (B) forest plot of the RD comparing the diagnostic yield of ROSE or without ROSE in the included studies; (C) forest plot of the RD comparing the sensitivity in diagnosing malignancy of ROSE or without ROSE in the included studies. RD, risk difference; ROSE, rapid on-site evaluation. 


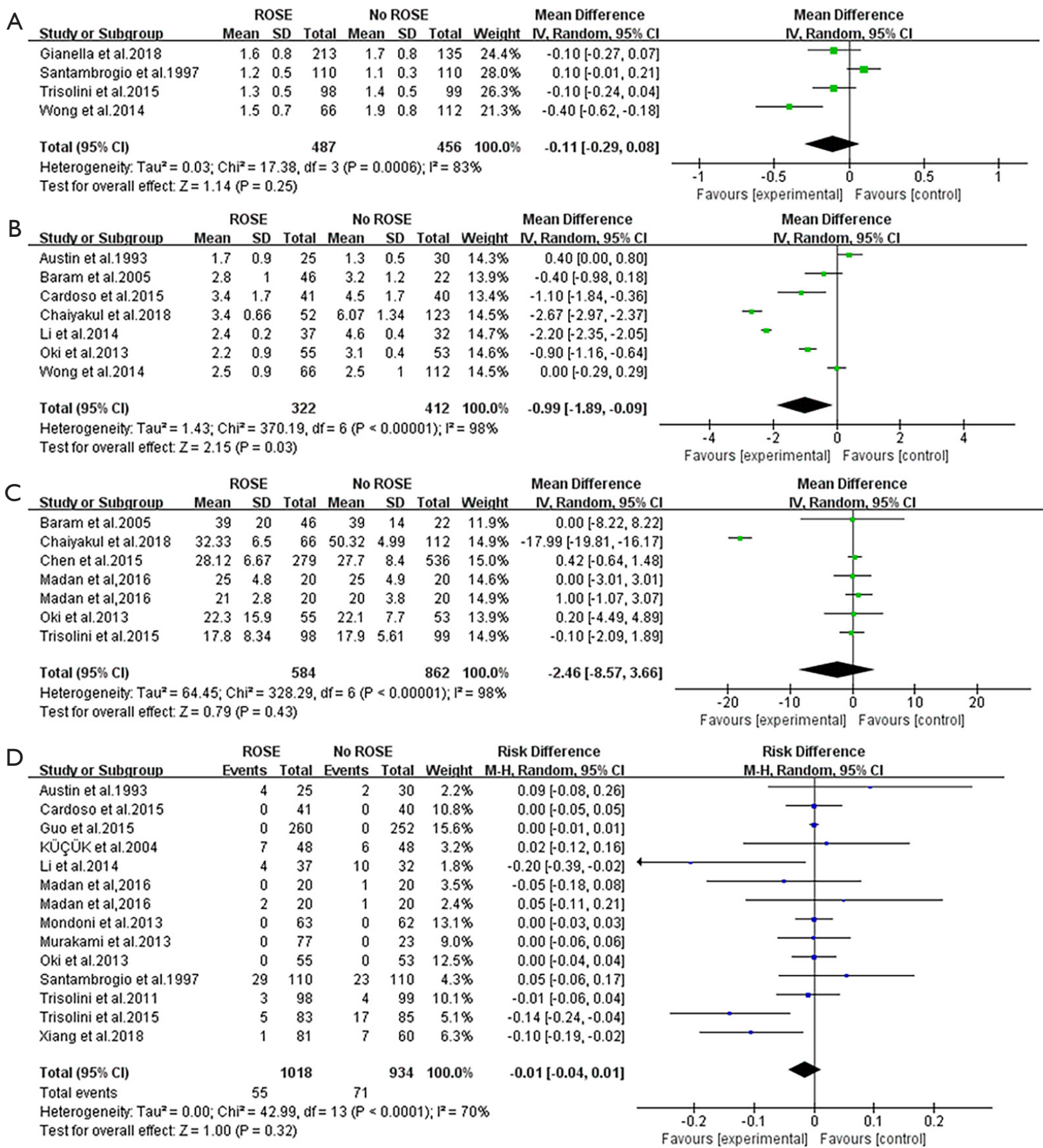

Figure 3 Forest plots of secondary endpoints. (A) Forest plot of the MD comparing the number of sampled sites of ROSE or without ROSE in the included studies; (B) forest plot of the MD comparing the number of needles passes of ROSE or without ROSE in the included studies; (C) forest plot of the MD comparing the procedure time of ROSE or without ROSE in the included studies; (D) forest plot of the $\mathrm{RD}$ comparing the complication rate of ROSE or without ROSE in the included studies. MD, mean difference; RD, risk difference; ROSE, rapid on-site evaluation. 


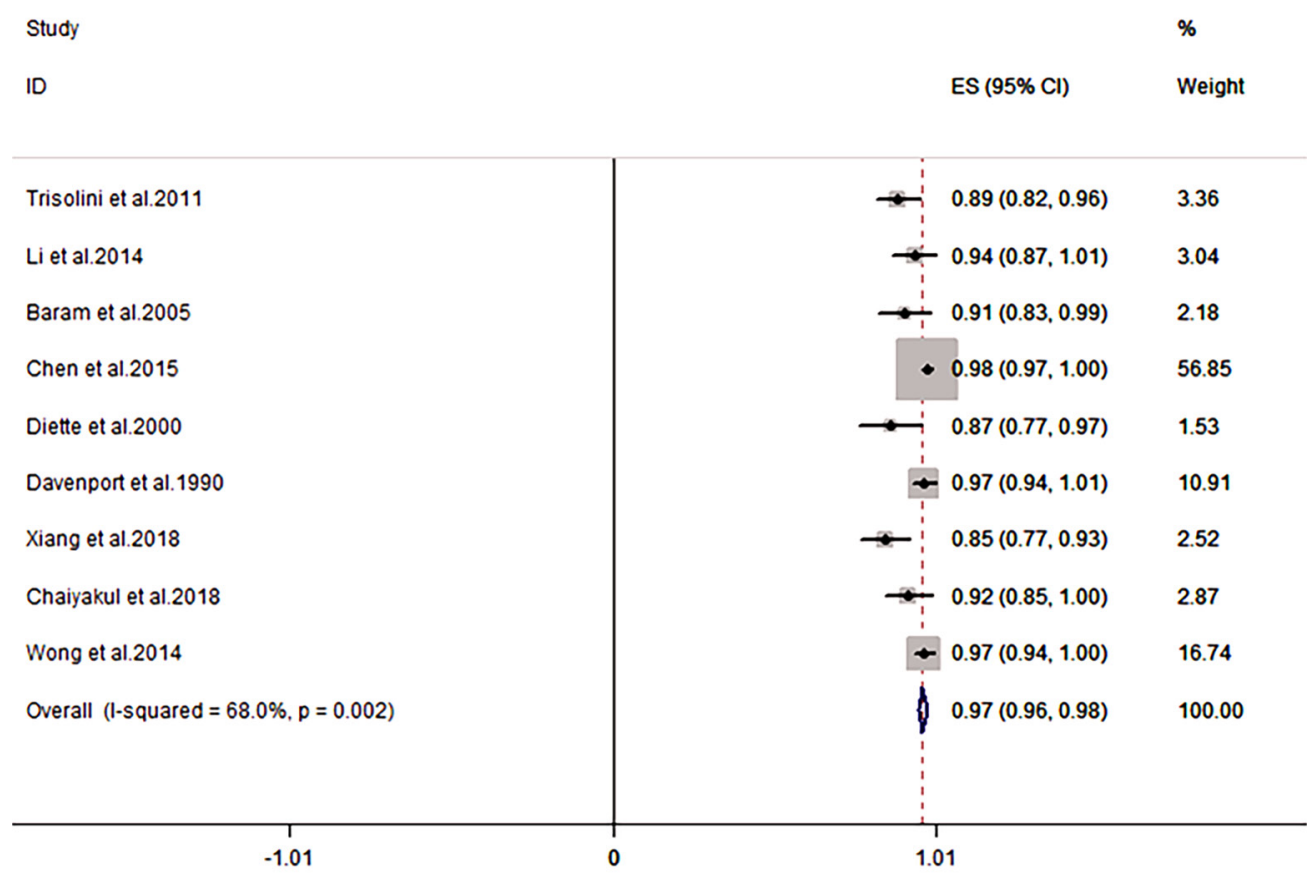

Figure 4 Forest plot of the pooled concordance between ROSE and final diagnosis in the included studies. ROSE, rapid on-site evaluation.

$(7,12,18,19,23,26)$ was not statistically different between the ROSE and No-ROSE group with pooled MD -0.46 (95\% CI: -0.87 to 3.66) (Figure 3C). Pooled complication rate between the two groups in 14 studies $(2,3,5,7,9,10,12,15,17,23-27)$ did not reach statistical difference [pooled RD $=-0.01$ (95\% CI: -0.04 to 0.01$)$ ] either (Figure 3D).

\section{Cost and ancillary test}

Li et al. (10) found that the cytology diagnostic cost decreased to $130.8 \pm 2.5$ RMB with ROSE from $140.3 \pm 4.6$ RMB. Bruno et al. (13) found that a considerable amount of euros (19413) was saved when using TBNA with ROSE as first diagnostic approach compared to using TBNA without ROSE when calculating the costs of combined procedures performed while diagnosing patients with mediastinal lymphadenopathy suspected for lung cancer.

Wong and his colleagues reported a larger proportion of satisfactory cell block after the utilization of ROSE (74\% pre-ROSE vs. 90\% post-ROSE) (28). Griffin et al. (14) reported that $92 \%$ of cell blocks were obtained with ROSE compared to $88 \%$ without ROSE, and more samples detected by immunochemistry (29\% vs. 15\%). Xiang et al. once reported similar results in immunochemistry. What's more, a randomized controlled trial carried out by Trisolini et al. (26) demonstrated that ROSE is associated with a $10 \%$ improvement of the complete genotyping achieved, though not reaching statistical significance, implies the prevention of redo procedures to gain genetic information for targeted therapy (Table S1).

\section{Concordance between ROSE and final diagnosis}

The combined concordance between ROSE and final diagnosis was $97 \%$ (95\% CI: 0.96-0.98, $\mathrm{I}^{2}=68 \%$ ) $(1,6,7,9,10,18,19,27,28)$ (Figure 4).

\section{Subgroup analysis and univariate analysis}

Subgroup analysis was conducted to assess the heterogeneity across studies in diagnostic yield and to amplify circumstances in which ROSE has more significance (Table 4). The pooled RD of diagnostic yield in RCTs was 0.10 (95\% CI: 0.03-0.17), and the pooled RD in not-RCTs was 0.16 (95\% CI: 0.12-0.20). The subgroup difference was not significant at a $\mathrm{P}$ value of 0.14 . The pooled RD $(95 \%$ $\mathrm{CI}$ ) of the diagnostic yield in studies mostly sampling lung masses/nodules was 0.07 (0.03-0.12), while the pooled RD (95\% CI) of studies mostly sampling lymph nodes was 0.16 $(0.12-0.20)$ and the subgroup difference was significant $(\mathrm{P}=0.005)$.According to the diagnostic method, the pooled 
Table 4 Subgroup analysis of diagnostic yield

\begin{tabular}{|c|c|c|c|c|}
\hline Subgroup & No. of studies & Pooled RD of diagnostic yield & Heterogeneity $\left(I^{2}\right)$ & Subgroup difference (P value) \\
\hline $\mathrm{RCT}$ & $7^{\star}$ & $0.10(95 \% \mathrm{Cl}: 0.03$ to 0.17$)$ & $55 \%$ & \\
\hline No-RCT & 11 & 0.16 (95\% Cl: 0.12 to 0.20$)$ & $21 \%$ & \\
\hline Main sampling sites & & & & 0.005 \\
\hline Hilar/mediastinal lymph nodes & $10^{*}$ & 0.07 (95\% Cl: 0.03 to 0.12$)$ & $0 \%$ & \\
\hline Diagnostic method & & & & 0.2 \\
\hline c-TBNA & 5 & $0.11(95 \% \mathrm{Cl}: 0.03$ to 0.18$)$ & $29 \%$ & \\
\hline EBUS-TBNA & 7 & 0.08 (95\% Cl: 0.04 to 0.12$)$ & $29 \%$ & \\
\hline Unselected patients & 4 & 0.11 (95\% Cl: -0.07 to 0.28$)$ & $77 \%$ & \\
\hline Suspected sarcoidosis & $1^{*}$ & 0.15 (95\% Cl: -0.24 to 0.54$)$ & $72 \%$ & \\
\hline Suspected/diagnosed lung cancer & 9 & $0.12(95 \% \mathrm{Cl}: 0.06$ to 0.18$)$ & $52 \%$ & \\
\hline
\end{tabular}

*, one study provided a diagnostic yield of c-TBNA and EBUS-TBNA separately. RD, risk difference; RCT, random controlled trial; c-TBNA, conventional transbronchial needle aspiration; EBUS, endobronchial ultrasound; TTFNA, transthoracic fine needle aspiration.

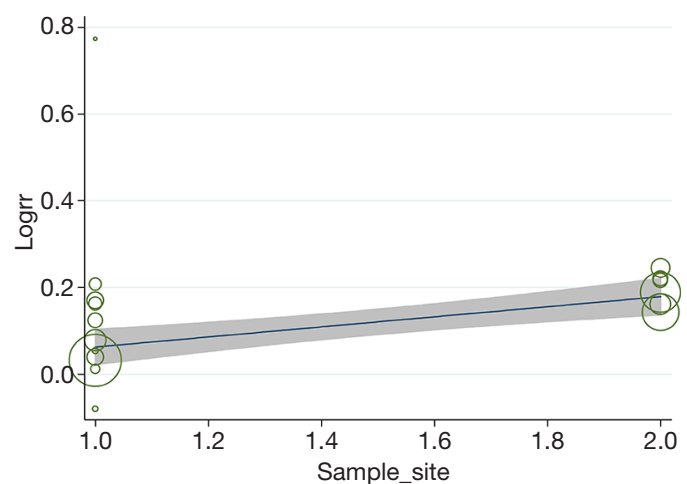

Figure 5 Meta-regression analysis of the primary sampling sites.

RD (95\% CI) of diagnostic yield was $0.11(0.03-0.18)$ with c-TBNA, 0.08 (0.04-0.12) with EBUS-TBNA, 0.16 (0.08-0.25) with TTFNA. The subgroup difference was not significant $(\mathrm{P}=0.20)$. A pooled $\mathrm{RD}$ of 0.12 (95\% CI: $0.06-0.18$ ) was found in the diagnostic yield of patients with suspected or diagnosed pulmonary malignancy, 0.15 (95\% CI: -0.24 to 0.54$)$ in suspected sarcoidosis and 0.11 (95\% CI: -0.07 to 0.28 ) in an unselected population.

Univariate analysis was performed on variables that considered as possible sources of heterogeneity; Meta- regression model showed that the main sampling sites (lung masses or lymph nodes) explained $94.24 \%$ between-study variability in the change in diagnostic yield due to ROSE (Figure 5).

\section{Publication bias}

The publication bias did not impact the adequacy rate, diagnostic yield and sensitivity for malignancy in this metaanalysis, as shown by the Begg's funnel plots (Figures S1-S3) and the $\mathrm{P}$ value of Begg's test for adequacy rate, diagnostic yield and sensitivity rate were $0.806,0.944$ and 0.436 respectively.

\section{Discussion}

This systemic review and meta-analysis firstly provided such a comprehensive description of the main results in all published studies comparing any aspect between ROSE and no-ROSE cohort in diagnosing pulmonary lesions and mediastinal lymph nodes at a single site. We figured out that, on average, ROSE contributed to a $12 \%, 14 \%$, and $10 \%$ rise in per-case adequate rate, diagnostic yield, and sensitivity for malignancy respectively. Although utilization 
of ROSE was inclined to decrease the number of needle passes $(-0.99,95 \%$ CI: -1.89 to -0.09$)$, ROSE neither impacted the procedure time nor complication rate. Subanalysis demonstrated a higher improvement of diagnostic yield with ROSE when diagnosed by CT-guided TTFNA, sampling pulmonary masses/nodules or applied to patients with suspected/diagnosed lung cancer and in no-RCT studies.

This meta-analysis illustrated that ROSE was associated with a statistical increase not only in adequate rate, but also in diagnostic yield and sensitivity for malignancy. Adequate means sufficient material provided, which was reported by per-specimen basis or per-case basis. Davenport offered a criterion for adequacy: the presence of malignant cells or numerous benign lymphoid cells that indicates the sample was obtained from a lymph node or a specific no neoplastic lesion (1). Even though the criteria in each study differed, the foundation of adequacy was cellularity. Improved adequacy rate means the improved quantity of cells gained from specimens. However, adequate is not sufficient for diagnostic. Once a specimen was described as adequate, it just means that it contains sufficient cells for a diagnosis. Whether a specific diagnosis can be made ultimately depended on the quality of the limited cells. Improved diagnostic yield means improved quality of specimens. Higher sensitivity for malignancy is another evidence for a better quality of specimens. Improved diagnostic yield means more diagnosis made but higher sensitivity for malignancy means more accurate the diagnosis was. Accordingly, the main finding of this meta-analysis is that ROSE is of great benefit to improve the quality and quantity of specimens.

Besides improvement in yield, ROSE was reported to have an impact on procedure details such as reducing the amount of sampling lesions or needle passes (1), shorting the procedure time (18) and eventually decreasing the complication rate $(9,10,27)$. The present analysis revealed that the use of ROSE contributed to a reduction in the number of needle passes (Figure 3B). In theory, a decrease in needle passes should lead to shorter procedure time and then less complication rate. For example, Chaiyakul et al. reported a reduction of needle passes and shorter procedure time accordingly and $\mathrm{Li}$ et al. reported reduced needle passes and correspondingly fewer complications. Nevertheless, there was a statistical difference between groups neither in procedure time nor in complication rate (Figure 3D). The probable reason for the indistinctive impact on procedure time might be that ROSE itself needed time such as staining and analyzing quick smears. Additional time of ROSE might weaken the impact of the reduction of needle passes on the whole procedure time. As for complication rate, though it is bound up with the amount of sampling lesions and needle passes, pooled complication rate between the two groups failed reach statistical difference. Further subgroup analysis suggested that complication rate was reduced in c-TBNA and EBUSTBNA but not in TTFNA (Figure S4). Possible explanation might be that the needle passes of these two studies contacted TTFNA didn't reduce. Apart from decreasing the needle passes (7), the lower requirement of additional procedures was recorded as well by several studies. In spite of indistinctive impact on procedure time and complication rate, the reduction of needle passes and additional procedures logically translated into cost saving. Li et al. (10) reported a slight decrease in cytologic diagnostic cost when utilizing ROSE, whereas Bruno et al. (13) reported a considerable reduction in the cost of combined procedures needed in the diagnostic process of suspected lung cancer. Despite the lack of sufficient literature for a meta-analysis, the incline of saving the cost is observable by reducing the needle passes and preventing from additional procedures.

What's more, in the current era of personalized medicine, lung cancer treatment such as chemotherapy and targeted therapy are assigned by histology and molecular testing. Xiang et al. and Griffin et al. (14) reported a higher rate of samples sufficient for immunochemistry, and then a higher rate of successful histological classification could be differentiated. Furthermore, Trisolini et al. (26) demonstrated that completing genotyping was obtained in more patients in the ROSE arm. ROSE could increase the number of samples with a high proportion of neoplastic cells, thus improved the rate of successful immunochemistry and molecular genotyping. There has been limited literature reporting on this aspect of ROSE by far. However, the advantage of the ancillary test would be promising in the coming era of individual pharmacotherapy.

All in all, ROSE is a useful technology for diagnosing pulmonary lesions with the advantage of improving the quality and quantity of specimens for histology and even molecular diagnosis, reducing the number of needle passes and saving the cost.

We found significant heterogeneity across studies in diagnostic yield, and we performed subgroup analyses to analyze the heterogeneity and try to figure out circumstances under which ROSE weighs more (Table 4). The leading cause of heterogeneity was mainly sampling 
sites. (We divided the sampling sites as mainly sampling pulmonary masses/nodules or hilar/mediastinal lymph nodes because most studies sampled both locations but always with a dominant one.) The rise of diagnostic yield was higher when primarily sampling solid pulmonary lesions than primarily sampling lymph nodes. Meta-regression further showed that this sub-analysis explained $94.24 \%$ between-study variability in the change in diagnostic yield due to ROSE. Recently, a meta-analysis comparing the diagnostic yield of TBNA demonstrated that the addition of ROSE does not enhance the diagnostic yield or reduce the procedure time of c-TBNA and EBUS-TBNA in mediastinal lymph node sampling (29). But this metaanalysis only included 5 RCTs sampling mediastinal lymph nodes by c-TBNA and EBUS-TBNA, there are additional RCTs sampling lung masses/nodules with other diagnostic procedures and reported a significant increase in diagnostic yield with ROSE $(3,5,24)$. Distinct cytological characteristics between solid lesions and adenopathy might explain this observation. As we know, ROSE guides the diagnostic process by assessing the specimen in the form of adequate or diagnostic. For lymph nodes, once diagnostic cells or numerous benign lymphoid cells were acquired, a specimen was considered to be adequate, and the diagnostic process terminated. For solid lesions, the process was inclined to end when a diagnostic specimen was gained. Acquisition of numerous benign lymphoid cells which regarded as adequate might be a non-diagnostic or false negative. In other words, ROSE affected the solid pulmonary lesions in the form of diagnostic yield while affected lymph nodes in the form of both adequacy and diagnostic yield. Thus it might limit the influence of ROSE on diagnostic yield when sampling lymph nodes. For different diagnostic methods, ROSE increased the diagnostic yield of all the three diagnostic methods as c-TBNA, EBUS-TBNA, and TTFNA. Meanwhile, the subgroup difference didn't reach statistical difference $(\mathrm{P}=0.20)$. What's more, the advantage of ROSE was not certified when applied to unselected patients or patients with suspected sarcoidosis, while a combined $12 \%$ increase was discovered when applying ROSE to patients with suspected or diagnosed lung cancer. Three of the 4 studies applied to unselected patients sampled lymph nodes for diagnosis $(9,11,17)$. As we hypothesized above, the acquisition of numerous benign lymphoid cells might be non-diagnostic or false-negative and limits the impact of ROSE when sampling lymph nodes. Similarly, when sampling lymph nodes, the influence of ROSE is even less in unselected patients with a higher rate of benign lesions compared to patients suspected with lung cancer. Therefore, we recommend ROSE to patients with suspected lung cancer rather than unselected patients, especially when sampling lymph nodes.

We also first evaluated the combined concordance between ROSE and final diagnosis. The pooled concordance was $97 \%$. High concordance between ROSE and definitive diagnosis signifies the remarkable accuracy of ROSE. The highly accurate ROSE in the diagnostic process can prevent inappropriate termination or unnecessary repetition of the sampling process.

Though detailed and comprehensive, our meta-analysis still has few limitations. First, to examine the role of ROSE in different patient groups, only one study (23) selected patients with suspected sarcoidosis. The impact of ROSE in diagnosing sarcoidosis still needs to be explored with more researches in the future. Besides, alternative evaluators (AEs) such as respiratory physicians and thoracic surgeons are advocated to perform ROSE for the limited availability of cytopathologists, and several studies reported comparative yield by AEs $(30,31)$. This review did not offer a comparison between cytopathologists and AEs. Finally, Davenport (1) once figured out that ROSE may have a more significant impact in peripheral pulmonary lesions while this metaanalysis failed to compare the effects of ROSE between central and peripheral pulmonary lesions with limited literature.

\section{Conclusions}

In conclusion, ROSE offers the opportunity to raise quality and quantity of specimens for histology and even molecular diagnosis, reduce the number of needle passes and save the cost in the diagnosing procedure without increasing the procedure time or complication rate. ROSE plays a more significant role when sampling pulmonary masses/ nodules and in the patient group with suspected lung cancer. Moreover, ROSE is highly consistent with the final diagnosis, which means that real-time feedback of ROSE is entirely accurate.

\section{Acknowledgments}

We sincerely appreciate other members of our research group. We cannot complete this work without your support. Funding: This study was funded by the grant 2016YFC1303800 from the National Key R\&D Program of China. 


\section{Footnote}

Conflicts of Interest: The authors have no conflicts of interest to declare.

Ethical Statement: The authors are accountable for all aspects of the work in ensuring that questions related to the accuracy or integrity of any part of the work are appropriately investigated and resolved.

\section{References}

1. Davenport RD. Rapid on-site evaluation of transbronchial aspirates. Chest 1990;98:59-61.

2. Austin JHM, Cohen MB. Value of having a cytopathologist present during percutaneous fine-needle aspiration biopsy of lung: Report of 55 cancer patients and metaanalysis of the literature. AJR Am J Roentgenol 1993;160:175-7.

3. Santambrogio L, Nosotti M, Bellaviti N, et al. CT-Guided fine-needle aspiration cytology of solitary pulmonary nodules: A prospective, randomized study of immediate cytologic evaluation. Chest 1997;112:423-5.

4. Saleh HA, Khatib G. Positive economic and diagnostic accuracy impacts of on-site evaluation of fine needle aspiration biopsies by pathologists. Acta Cytologica 1996;40:1227-30.

5. Küçük CU, Yilmaz A, Yilmaz A, et al. Computed tomography-guided transthoracic fine-needle aspiration in diagnosis of lung cancer: A comparison of single-pass needle and multiple-pass coaxial needle systems and the value of immediate cytological assessment. Respirology 2004;9:392-6.

6. Diette GB, White JP, Terry P, et al. Utility of on-site cytopathology assessment for bronchoscopic evaluation of lung masses and adenopathy. Chest 2000;117:1186-90.

7. Sun J, Xie F, Zheng X, et al. Learning curve of electromagnetic navigation bronchoscopy for diagnosing peripheral pulmonary nodules in a single institution. Transl Cancer Res 2017;6:541-51.

8. Chin R Jr, McCain TW, Lucia MA, et al. Transbronchial needle aspiration in diagnosing and staging lung cancer: How many aspirates are needed? Am J Respir Crit Care Med 2002;166:377-81.

9. Trisolini R, Cancellieri A, Tinelli C, et al. Rapid on-site evaluation of transbronchial aspirates in the diagnosis of hilar and mediastinal adenopathy a randomized trial. Chest 2011;139:395-401.

10. Li K, Liu M, Jiang S, et al. The value of transbronchial needle aspiration combined with rapid on-site evaluation of cytology in the diagnosis of lung cancer. Zhongguo Fei Ai Za Zhi 2014;17:215-20.

11. Yarmus L, Van Der Kloot T, Lechtzin N, et al. A randomized prospective trial of the utility of rapid on-site evaluation of transbronchial needle aspirate specimens. J Bronchology Interv Pulmonol 2011;18:121-7.

12. Oki M, Saka H, Kitagawa C, et al. Rapid on-site cytologic evaluation during endobronchial ultrasound-guided transbronchial needle aspiration for diagnosing lung cancer: A randomized study. Respiration 2013;85:486-92.

13. Bruno P, Ricci A, Esposito MC, et al. Efficacy and cost effectiveness of rapid on site examination (ROSE) in management of patients with mediastinal lymphadenopathies. Eur Rev Med Pharmacol Sci 2013;17:1517-22.

14. Griffin AC, Schwartz LE, Baloch ZW. Utility of onsite evaluation of endobronchial ultrasound-guided transbronchial needle aspiration specimens. Cytojournal 2011;8:20.

15. Guo H, Liu S, Guo J, et al. Rapid on-site evaluation during endobronchial ultrasound-guided transbronchial needle aspiration for the diagnosis of hilar and mediastinal lymphadenopathy in patients with lung cancer. Cancer Lett 2016;371:182-6.

16. Moher D, Shamseer L, Clarke M, et al. Preferred reporting items for systematic review and meta-analysis protocols (PRISMA-P) 2015 statement. Systematic Reviews 2015;4:1.

17. Cardoso AV, Neves I, Magalhães A, et al. The value of rapid on-site evaluation during EBUS-TBNA. Rev Port Pneumol 2015;21:253-8.

18. Chaiyakul S. Endobronchial ultrasound-guided transbronchial needle aspiration for the diagnosis of central intrapulmonary lesions not visible by conventional bronchoscopy. J Med Assoc Thailand 2018;101:939-47.

19. Chen $\mathrm{CH}$, Cheng $\mathrm{WC}, \mathrm{Wu} \mathrm{BR}$, et al. Improved diagnostic yield of bronchoscopy in peripheral pulmonary lesions: Combination of radial probe endobronchial ultrasound and rapid on-site evaluation. J Thorac Dis 2015;7:S418-25.

20. Collins BT, Chen AC, Wang JF, et al. Improved laboratory resource utilization and patient care with the use of rapid on-site evaluation for endobronchial ultrasound fine-needle aspiration biopsy. Cancer Cytopathol 2013;121:544-51.

21. Gianella P, Soccal PM, Plojoux J, et al. Utility of Rapid On-Site Cytologic Evaluation during Endobronchial Ultrasound-Guided Transbronchial Needle Aspiration in 
Malignant and Nonmalignant Disease. Acta Cytologica 2018;62:380-5.

22. Kern I, Gabric S, Triller N, et al. Telecytology for rapid assessment of cytological specimens. J Telemed Telecare 2012;18:86-9.

23. Madan K, Dhungana A, Mohan A, et al. Conventional Transbronchial Needle Aspiration Versus Endobronchial Ultrasound-guided Transbronchial Needle Aspiration, with or Without Rapid On-Site Evaluation, for the Diagnosis of Sarcoidosis: A Randomized Controlled Trial. J Bronchology Interv Pulmonol 2017;24:48-58.

24. Mondoni M, Carlucci P, Di Marco F, et al. Rapid onsite evaluation improves needle aspiration sensitivity in the diagnosis of central lung cancers: A randomized trial. Respiration 2013;86:52-8.

25. Murakami Y, Oki M, Saka H, et al. Endobronchial ultrasound-guided transbronchial needle aspiration in the diagnosis of small cell lung cancer. Respir Investig 2014;52:173-8.

26. Trisolini R, Cancellieri A, Tinelli C, et al. Randomized trial of endobronchial ultrasound-guided transbronchial needle aspiration with and without rapid on-site evaluation for lung cancer genotyping. Chest 2015;148:1430-7.

Cite this article as: Chen $\mathrm{X}$, Wan B, Xu Y, Song Y, Zhan P, Huang L, Liu H, Lin D, Lv T. Efficacy of rapid on-site evaluation for diagnosing pulmonary lesions and mediastinal lymph nodes: a systematic review and meta-analysis. Transl Lung Cancer Res 2019;8(6):1029-1044. doi: 10.21037/ tlcr.2019.12.13
27. Xiang Q, Wan T, Hu Q, et al. Value of C-ROSE During EBUS-TBNA to Obtain the Tissue Sample in the Diagnosis of Lung Cancer. Zhongguo Fei Ai Za Zhi 2018;21:833-40.

28. Wong RWM, Thai A, Khor YH, et al. The Utility of Rapid On-Site Evaluation on Endobronchial Ultrasound Guided Transbronchial Needle Aspiration: Does It Make a Difference? J Resp Med 2014;2014:Article ID 245974.

29. Sehgal IS, Dhooria S, Aggarwal AN, et al. Impact of Rapid On-Site Cytological Evaluation (ROSE) on the Diagnostic Yield of Transbronchial Needle Aspiration During Mediastinal Lymph Node Sampling: Systematic Review and Meta-Analysis. Chest 2018;153:929-38.

30. Hopkins E, Moffat D, Smith C, et al. Accuracy of rapid on-site evaluation of endobronchial ultrasound guided transbronchial needle aspirates by respiratory registrars in training and medical scientists compared to specialist pathologists-an initial pilot study. J Thorac Dis 2018;10:3922-7.

31. Jeffus S, Meena N, Massoll N, et al. Rapid on-site evaluation: A comparison of performance of pulmonologist to cytopathologist. Lab Invest 2015;95:93A-94A. 


\section{Supplementary}

Table S1 Detailed information about cost and ancillary test

\begin{tabular}{|c|c|c|c|}
\hline Author year & Cost or Ancillary test & $\mathrm{R}$ & NR \\
\hline Bruno et al., 2013 & Total expenses incurred for the diagnostic procedure & 61,224 euro & 80,637 euro \\
\hline Wong et al., 2014 & Satisfactory cell block & $90 \%$ & $74 \%$ \\
\hline Griffin et al., 2010 & Cell block & $92 \%$ & $88 \%$ \\
\hline Xiang et al., 2018 & Immunochemistry stains & $40.74 \%$ & $15 \%$ \\
\hline Trisolini et al., 2015 & Complete genotyping & $85.7 \%$ & $80.5 \%$ \\
\hline
\end{tabular}

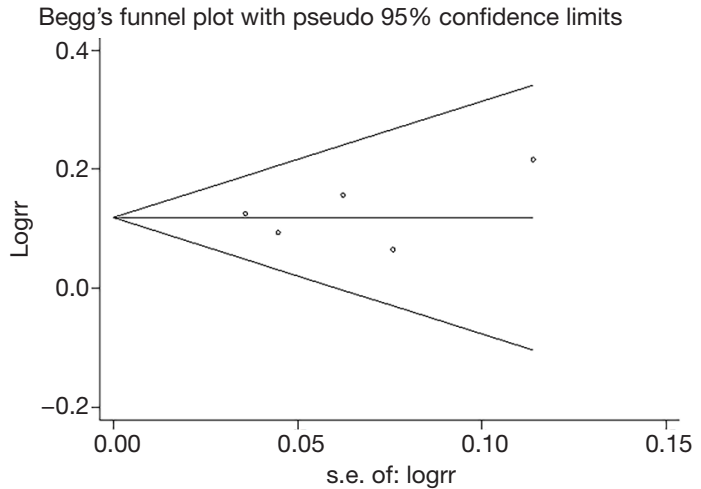

Figure S1 Funnel plot evaluating the adequacy of ROSE or without ROSE in the included studies. ROSE, rapid on-site evaluation.

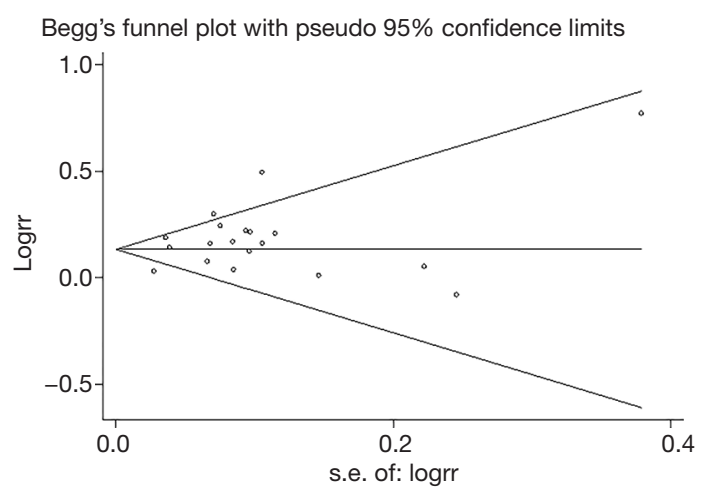

Figure S2 Funnel plot evaluating the diagnostic yield of ROSE or without ROSE in the included studies. ROSE, rapid on-site evaluation.

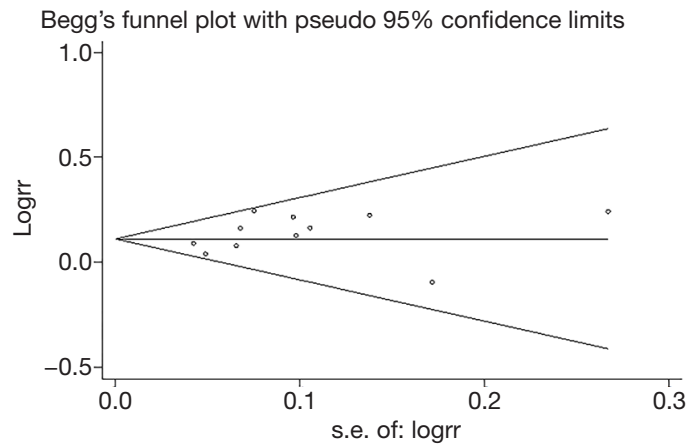

Figure S3 Funnel plot evaluating sensitivity for malignancy of ROSE or without ROSE in the included studies. ROSE, rapid onsite evaluation. 


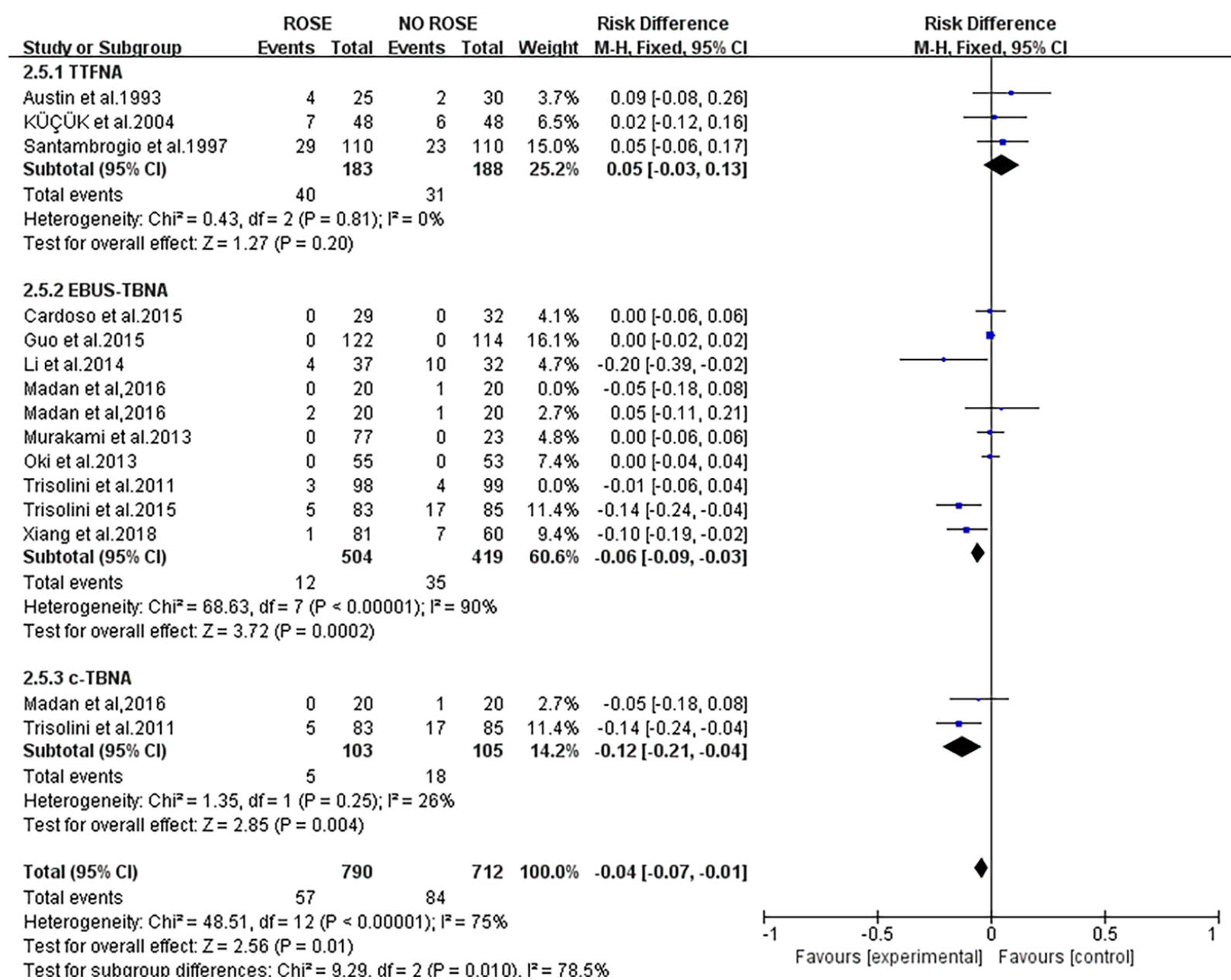

Figure S4 Forest plot of the RD comparing the complication rate of ROSE or without ROSE in subgroup analysis of different diagnostic methods. RD, risk difference; ROSE, rapid on-site evaluation. 